\title{
A double-blind, multicentre, placebo-controlled study of tiludronate in Paget's disease of bone
}

\author{
William D Fraser, Trevor C Stamp, Robert A Creek, James P Sawyer, Christopher Picot
}

\begin{abstract}
Summary
A multicentre, randomised, placebo-controlled, dose-ranging study was conducted to investigate the therapeutic activity and sustained efficacy of tiludronate $(200 \mathrm{mg}$, $400 \mathrm{mg}$ and $600 \mathrm{mg}$ once daily) taken orally for 12 weeks in patients with Paget's disease. Serum alkaline phosphatase concentrations were compared with baseline at weeks 12 and 24; treatment success was defined as a $50 \%$ reduction compared with baseline. Changes in the hydroxyproline: creatinine ratio were also measured. Pain was assessed using the Huskisson Visual Analogue Scale and by questionnaire. Patients completing at least 11 weeks of treatment were followed-up 18 months later by postal questionnaire.
\end{abstract}

Significantly greater numbers of patients in the tiludronate groups successfully responded to treatment compared with the placebo group. A dose-response was observed; the percentage of patients responding to treatment being $31 \%$ ( $200 \mathrm{mg}), 52 \%$ $(400 \mathrm{mg})$ and $82 \%(600 \mathrm{mg})$ at week 12 and $45 \%(200 \mathrm{mg}), 70 \%(400 \mathrm{mg})$ and $82 \%(600$ mg) at week 24 . Tiludronate treatment also significantly reduced hydroxyproline:creatinine ratios compared with placebo, again showing a dose response. Dose-related gastrointestinal symptoms were the commonest adverse events, occurring in $2.4 \%$, $11.0 \%, 5.5 \%$ and $18.9 \%$ of patients receiving placebo and tiludronate 200,400 and $600 \mathrm{mg}$ daily, respectively. The response to oral tiludronate was sustained for more than 18 months in some patients and there was evidence of a reduction in the longer term complications of the disease. These results show that oral tiludronate is an effective, well-tolerated treatment for Paget's disease; the $400 \mathrm{mg}$ once daily dose appears to offer the optimum balance of efficacy and tolerance.

Sanofi Winthrop Ltd, One Onslow Street, Guildford, Surrey GU1 4YS, UK

RA Creek

JP Sawyer

Sanofi Recherche, 74-82 Avenue

Raspail, 94255

Gentilly Cedex, France

C Picot

Correspondence to Dr RA Creek

Accepted 12 February 1997 approximately $4.6 \%$ of the population over 55 years of age, ${ }^{1}$ and represents a significant cause of morbidity. Paget's disease of bone is marked by dramatic increases in the number of osteoclasts, resulting in increased, chaotic, bone resorption.
This leads to excessive osteoblastic activity, with a variable mixture of immature 'woven' bone and irregular, mature lamellar bone being laid down. Increased bone resorption is associated with a marked increase in urinary hydroxyproline excretion whereas increased osteoblast activity is indicated by increases in serum alkaline phosphatase concentrations.

The bone changes associated with Paget's disease are asymptomatic in the majority of patients but complications such as fractures (11\%) or deformity $(17 \%)$ can occur. ${ }^{2}$ Pain, the main symptom of Paget's disease, can arise from the Pagetic bone itself or from complications, especially osteoarthritis, secondary to Paget's disease. ${ }^{2-3}$

Two main classes of drug therapy are currently available for the treatment of Paget's disease. The calcitonins are moderately successful in suppressing disease activity, reducing urinary hydroxyproline and serum alkaline phosphatase concentrations by approximately $55 \%$ during treatment. ${ }^{4}$ However, relapse occurs rapidly when calcitonin is stopped and approximately $20 \%$ of patients become resistant to ongoing treatment. ${ }^{5}$ Another disadvantage of calcitonin treatment is the need for parenteral injection, although intranasal preparations are being developed. In addition, adverse gastrointestinal side effects and flushing can be troublesome. ${ }^{6-9}$

A second class of drugs, the bisphosphonates, inhibit osteoclastic resorption and thus reduce bone turnover. ${ }^{10}$ They have demonstrated efficacy in Paget's disease with a dosedependent response. ${ }^{11}$ Disodium etidronate is widely used for the treatment of Paget's disease although its value is compromised by dosedependent inhibition of bone mineralisation. ${ }^{12}$ Tiludronate (chloro-4-phenyl thiomethylene bisphosphonate; SR 41319B) is a second generation bisphosphonate with experimental anti-osteoclastic activity. ${ }^{13}$ In an earlier doubleblind clinical study, $800 \mathrm{mg} /$ day of a capsule formulation proved the optimum dose in patients with Paget's disease. ${ }^{14}$ A subsequent tablet formulation of tiludronate, with two to three times greater bioavailability, has been shown, in an open study using $400 \mathrm{mg} /$ day, to effect similar reductions in serum alkaline phosphatase and urinary hydroxyproline ( $\mathrm{Re}-$ ginster et al, unpublished observations). We therefore sought to confirm the efficacy and optimum dose of tiludronate tablets in patients with Paget's disease of bone in a placebocontrolled, double-blind, randomised, multicentre dose-ranging study. 


\section{Patients and methods}

PATIENT POPULATION

A total of 112 patients, of either sex (age $\geqslant 18$ years) with diagnosis of Paget's disease confirmed by scintigraphy $(63 \%)$ and/or radiography $(92 \%)$ entered the study. Serum alkaline phosphatase concentration had to be at least twice the upper limit of normal at the local laboratory. Patients were ineligible for study entry if they fulfilled any of the following criteria: prior treatment with bisphosphonates other than etidronate within the past two years; treatment with etidronate, mithramycin or calcitonin within six months; prior treatment at any time if the current serum alkaline phosphatase concentration was less than $30 \%$ above the lowest concentration then achieved; recent fracture or confinement to bed; current peptic ulceration; clinically significant hepatic, renal or haematological disorder; pre-menopausal women; malignant neoplasia within the previous five years or breast malignancy within the previous 10 years; recent change in dose of hormone replacement therapy, vitamin $\mathrm{D}$ or corticosteroids. Withdrawal from the trial was permissible at any time.

\section{STUDY DESIGN}

The double-blind, randomised study consisted of four parallel treatment groups receiving a single dose of placebo, or oral tiludronate (200 $\mathrm{mg}, 400 \mathrm{mg}$ or $600 \mathrm{mg} /$ day) for 12 weeks. Patients were recruited from 16 hospitals throughout the UK. A follow-up of patients who had completed at least 11 weeks of treatment was carried out $\mathbf{1 8}$ months after the completion of the last patient in the trial using a postal questionnaire. This assessed the need for, and time to, first retreatment for Paget's disease. The number of patients suffering from complications of Paget's disease (defined as any orthopaedic (including fractures), neurological (including pain), cardiovascular or sarcomatous event) were assessed. Local laboratory serum alkaline phosphatase concentrations from routine out-patient visits since the end of the main trial were also recorded.

All patients gave written, informed consent and each centre obtained written approval from local ethics committees. The study was conducted in accordance with the Declaration of Helsinki as revised in 1989.

Patients were allocated sequential study numbers and randomly assigned to one of the four treatment groups. Patients attended a total of six visits: at baseline (week 0), after two, four, eight and 12 weeks treatment, and 24 weeks after baseline. Medication was taken in the morning with water, at least two hours before or after taking food.

\section{ASSESSMENTS}

Blood samples were taken at every visit and analysed independently at a single central laboratory, using automated techniques for all routine haematology and biochemistry (including serum calcium and phosphate) tests.
Serum alkaline phosphatase concentrations were the primary endpoint for efficacy. Fasting urine samples were collected over a period of at least two hours after an overnight void. Hydroxyproline concentrations were measured by a cation exchange resin system and quantitative spectrophotometric colorimetry.

Medical histories and a full clinical examination were completed at the first visit. A 12lead electroencephalogram was performed at weeks 0 and 12 . Compliance was assessed by tablet counts and concomitant medication and adverse events were recorded in detail throughout the study.

Pain was a secondary efficacy criterion. A visual analogue scale ${ }^{15}$ was used for patients to assess their Pagetic pain. The scale ranged from 'no pain' to 'agonising pain'. In addition, at each visit, symptomatic bone pain was assessed by the physician as 'none', 'some' or 'constant', with its severity at rest and on movement assessed as 'none', 'mild', 'moderate', or 'severe'.

\section{STATISTICAL ANALYSIS}

The study was intended to have an $80 \%$ power of detecting a true difference of $40 \%$ in success rates between any two treatment groups $(\alpha=0.05$, two-sided), with a total of at least 100 patients. Data were analysed on an 'intention to treat' basis. A successful response was defined as at least a $50 \%$ reduction in serum alkaline phosphatase concentration after 12 weeks treatment; patients whose serum alkaline phosphatase concentrations decreased by $25 \%$ or less compared with week 0 were defined as resistant.

Between-group comparisons of the proportion of patients with a successful response and those resistant to treatment were made at weeks 12 and 24 . Two by two contingency tables of each pair-wise comparison were analysed by Fisher's exact test and the p-values were subsequently corrected by the Sidak method for multiple testing.

Serum alkaline phosphatase concentrations and hydroxyproline:creatinine ratios were compared at weeks 12 and 24 by analysis of variance (ANOVA). Data were log transformed and presented as adjusted geometric mean ratios to allow for centre and baseline variability. Multiple comparisons of the least square means using the Sidak t-test were presented as Sidak-corrected p-values and simultaneous $95 \%$ confidence intervals. The associations between the gastrointestinal adverse events and concomitant use of nonsteroidal anti-inflammatories or a history of gastric disorder were analysed using the Breslow-Day test.

Data from the follow-up questionnaire were analysed using the Chi-squared statistic unless all the questions were not answered in which case a Fisher's exact test was used. All the serum alkaline phosphatase samples collected during the follow-up period were analysed locally. To allow comparison, these data were converted to a percentage of the mid point of the appropriate reference range. 


\section{Results}

Patient characteristics and randomisation at entry are given in table 1 . The most prevalent lesion sites at recruitment were the pelvis ( $75 \%$ of patients) and the lumbar spine $(39 \%) ; 30 \%$ of patients had disease at one site only and $50 \%$ of patients had received no previous therapy for Paget's disease. Seven patients were withdrawn for adverse events (one on placebo, three on $200 \mathrm{mg}$, one on $400 \mathrm{mg}$ and two on $600 \mathrm{mg}$ ), two died (both on $200 \mathrm{mg}$ ), five were withdrawn for protocol violation (three on placebo, one each on 400 $\mathrm{mg}$ and $600 \mathrm{mg}$ ), and four were lost to followup (two on placebo, one each on $200 \mathrm{mg}$ and $600 \mathrm{mg}$ ). Three patients, all on placebo, received alternative treatment for Paget's disease during the initial 12 week follow-up period. Patient characteristics at entry were similar in each group (table 1), although known duration of disease was longer in the 400-mg dose group. The mean compliance calculated from tablet counts was $>96 \%$ in each treatment group.

\section{EFFICACY}

No changes in efficacy parameters were observed in patients treated with placebo. The percentage of patients achieving a $\geqslant 50 \%$ reduction in serum alkaline phosphatase concentrations on each treatment is given in table 2. All tiludronate doses were significantly more effective than placebo at weeks 12 and 24 $(\mathrm{p}<0.0001$ except for the $200 \mathrm{mg}$ dose at week $12(\mathrm{p}<0.05))$. The tiludronate response was dose-related and increased over time (figure 1). Serum alkaline phosphatase levels fell significantly more with $600 \mathrm{mg}$ than with 200 $\mathrm{mg}$ at week $12(\mathrm{p}<0.001 ; 95 \%$ confidence intervals (CI) $0.524-0.837$ ) and at week 24 $(\mathrm{p}<0.001 ; 95 \%$ CI $0.463-0.832)$, and more than $400 \mathrm{mg}$ at week $12(\mathrm{p}=0.043 ; 95 \% \mathrm{CI}$ $0.630-0.995)$. The reduction in serum alkaline phosphatase was evident from two weeks and continued in the 12 weeks after treatment ended. There was no evidence to suggest that efficacy differed in patients who had received previous bisphosphonate treatment $(\mathrm{p}>0.20$; type III sum of squares). Furthermore, any differences in efficacy between treatment groups were found to be unrelated to the duration of Paget's disease ( $p>0.23$; type III sum of squares).

Normal serum alkaline phosphatase levels $(\leqslant 115 \mathrm{IU} / \mathrm{l})$ were achieved in a significantly higher percentage of $200 \mathrm{mg}$ (31\%), $400 \mathrm{mg}$ $(39 \%)$ and $600 \mathrm{mg}(44 \%)$ recipients than placebo recipients $(0 \%)$ at 24 weeks $(\mathrm{p}<0.05)$. Resistance to treatment by week 24 was $91 \%$ for placebo, $8 \%$ for tiludronate 200 $\mathrm{mg}$ and $4 \%$ for both tiludronate $400 \mathrm{mg}$ and $600 \mathrm{mg}$ groups $(\mathrm{p}<0.05$ for all group comparisons to placebo).

Changes in the geometric mean hydroxyproline:creatinine ratio over time for each treatment are illustrated in figure 2. Hydro-

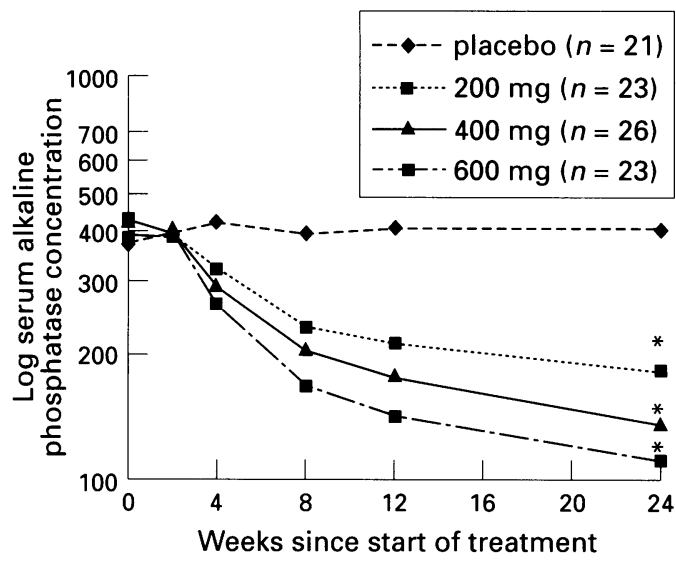

Figure 1 Effect of tiludronate $(200,400$ or $600 \mathrm{mg}$ daily) on mean serum alkaline phosphatase concentrations. All the treatment groups were significantly lower than placebo $(\mathrm{p}<0.001) . n=n$ at week 24 .

Table 2 Percentage of patients with successful response ( $\geqslant 50 \%$ reduction in serum alkaline phosphatase levels compared with baseline)

\begin{tabular}{lllll}
\hline \multirow{5}{*}{ Tiludronate } \\
\cline { 3 - 5 } Week & Placebo & $200 \mathrm{mg}$ & $400 \mathrm{mg}$ & $600 \mathrm{mg}$ \\
\hline 4 & 0 & 0 & 7 & 11 \\
8 & 0 & 14 & $35^{\star}$ & $711^{\star \dagger}$ \\
12 & 0 & $31^{\star}$ & $52^{\star \star}$ & $82 \dagger$ \\
24 & 0 & $45^{\star \star}$ & $69^{\star \star}$ & $82 \dagger$
\end{tabular}

$\star$ Significantly different from placebo $(\mathrm{p}<0.05) .{ }^{\star \star}$ Significantly different from placebo $(p<0.001)$. †Significantly different from placebo and tiludronate $200 \mathrm{mg}$ $(\mathrm{p}<0.001)$. † Significantly different from placebo, tiludronate $200 \mathrm{mg}(\mathrm{p}<0.0001)$ and $400 \mathrm{mg}(\mathrm{p}<0.005)$

Table 1 Patient characteristics at entry

\begin{tabular}{|c|c|c|c|c|c|}
\hline & \multirow[b]{2}{*}{$\begin{array}{l}\text { Placebo } \\
(n=26)\end{array}$} & \multicolumn{3}{|l|}{ Tiludronate } & \multirow[b]{2}{*}{$\begin{array}{l}\text { Total } \\
(n=112)\end{array}$} \\
\hline & & $\begin{array}{l}200 \mathrm{mg} \\
(n=29)\end{array}$ & $\begin{array}{l}400 \mathrm{mg} \\
(n=29)\end{array}$ & $\begin{array}{l}600 m g \\
(n=28)\end{array}$ & \\
\hline $\operatorname{Sex}(M / F)$ & $12 / 14$ & $12 / 17$ & $18 / 11$ & $18 / 10$ & $60 / 52$ \\
\hline Race (Caucasian/Negroid) & $26 / 0$ & $29 / 0$ & $29 / 0$ & $27 / 1$ & $111 / 1$ \\
\hline Mean age (years) (SD) & $69(9.3)$ & $70(7.8)$ & $72(7.6)$ & $68(7.6)$ & $70(8.1)$ \\
\hline $\begin{array}{l}\text { Mean time since diagnosis of } \\
\text { Paget's disease (years) (SD) }\end{array}$ & $8.5(7.0)$ & $7.1(9.0)$ & $11.1(9.6)$ & $5.5(8.0)$ & $8.1(8.6)^{\star}$ \\
\hline Alkaline phosphatase ${ }^{\star \star}(\mathrm{IU} / \mathrm{l})$ & $388(139-1611)$ & $397(174-1795)$ & $435(197-1614)$ & $436(131 \dagger-1268)$ & $414(131-1795)$ \\
\hline Hydroxyproline: creatinine ratio $\dagger^{\dagger}$ & $\begin{array}{l}0.05(0.01-0.21) \\
(n=22)\end{array}$ & $\begin{array}{l}0.06(0.01-0.38) \\
(n=24)\end{array}$ & $\begin{array}{l}0.07(0.02-0.55) \\
(n=24)\end{array}$ & $\begin{array}{l}0.05(0.01-0.40) \\
(n=24)\end{array}$ & $\begin{array}{l}0.06(0.01-0.55) \\
(n=94)\end{array}$ \\
\hline No of patients with Pagetic bone pain (\%) & $17(65)$ & $18(62)$ & $19(66)$ & $16(57)$ & $70(63)$ \\
\hline
\end{tabular}

${ }^{\star} \mathrm{p}>0.230$ : type III sum of squares ${ }^{\star \star}$ Reference range $25-115 \mathrm{IU} / \mathrm{l}$; ranges in parentheses $\dagger$ This patient was subsequently withdrawn as his serum alkaline phosphatase level was not $\geqslant$ twice the upper limit of normal at the local laboratory. $\dagger+$ Reference range $0.005-0.036$; ranges in parentheses 
xyproline:creatinine ratios were substantially decreased by tiludronate, but not by placebo, with a dose-response effect. The most rapid reduction of hydroxyproline occurred in the first four weeks of treatment. Tiludronate 400 $\mathrm{mg}$ and $600 \mathrm{mg}$ decreased hydroxyproline: creatinine ratios to a significantly greater extent than placebo at week $12(\mathrm{p}<0.001)$ and week 24 ( $\mathrm{p}<0.05)$. Although tiludronate $200 \mathrm{mg}$ decreased the hydroxyproline:creatinine ratio by more than $34 \%$ compared with placebo, the reduction was not statistically significant; 600 mg was significantly more effective than 200 $\mathrm{mg}$ at weeks 12 and $24(\mathrm{p}<0.05)$, but other between-treatment differences were not statistically significant.

Only 70 out of 112 patients (63\%) complained of Pagetic bone pain on entry. The proportion of patients complaining of bone pain at weeks 12 and 24 was greatest with placebo $(57 \%$ and $67 \%$, respectively) and lowest with tiludronate $600 \mathrm{mg}(36 \%$ and $37 \%$, respectively). However, there were no significant differences between any of the treatment groups at week 12 or 24 . The number of patients reporting Pagetic bone pain at entry were $17,18,19$ and 16 for placebo, $200 \mathrm{mg}, 400 \mathrm{mg}$ and $600 \mathrm{mg}$, respectively. By week 24 the numbers were $16,14,13$ and 10, respectively, although patients reporting pain at week 24 did not necessarily report pain at entry. Median Visual Analogue Scale scores for pain were lower in the tiludronate $600 \mathrm{mg}$ group at weeks 12 and 24 ( 0 and $0 \mathrm{~mm}$, respectively) than on placebo

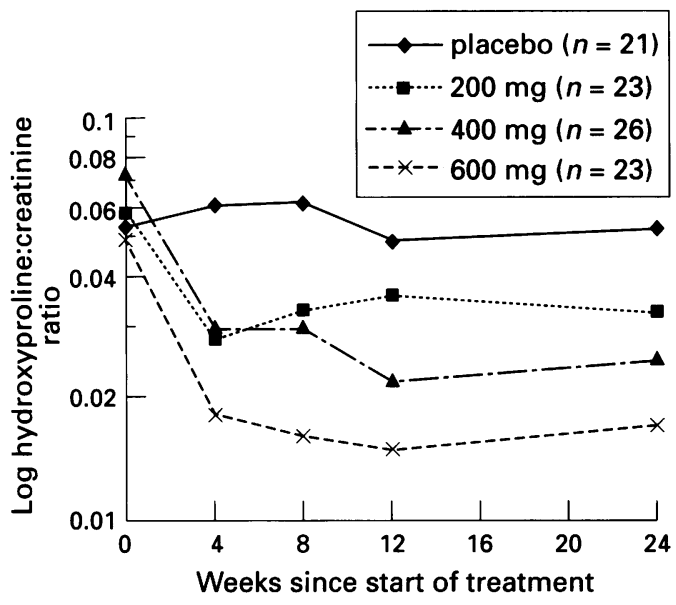

Figure 2 Effect of tiludronate (200, 400 or $600 \mathrm{mg}$ daily) on mean serum hydroxyproline:creatinine ratios
(15 and $27 \mathrm{~mm}$, respectively) but there were no significant differences between any of the treatment groups.

\section{SAFETY}

The few changes in haematological or biochemical safety measurements that were of clinical significance are described below. One 62-year-old man (600 mg dose) developed epigastric pain, nausea and an elevated serum creatinine concentration ( $182 \mu \mathrm{mol} / \mathrm{l}$; reference range $45-125$ ) at week 24 . During treatment, creatinine concentrations had remained stable and within the reference range. No significant changes in liver function tests were observed during the trial.

One 79-year-old man (600 mg dose) was found to have raised liver enzymes during the study. On weeks 8 and 12 his alanine transaminase concentrations were above the reference range ( $47 \mathrm{IU} / 1$ and $43 \mathrm{IU} / 1$, respectively; reference range 5-40 IU/1), and throughout the entire duration of the study his $\gamma$-glutamyl transpeptidase concentrations were also above the reference range (week 0: $126 \mathrm{IU} / 1$, week 2: $99 \mathrm{IU} / 1$, week 4: $90 \mathrm{IU} / 1$, week 8: $86 \mathrm{IU} / 1$, week 12: $85 \mathrm{IU} / 1$ and week 24: $67 \mathrm{IU} / 1$; reference range $0-60 \mathrm{IU} / \mathrm{l})$. With the exception of the $\gamma$ glutamyl concentration at week 0 , none of these raised enzyme concentrations were considered to be clinically significant.

A clinically significant eosinophilia was reported in a 69-year-old man (placebo) at week 8 of the study $\left(1.6 \times 10^{9} / 1\right.$; reference range $\left.<0.5 \times 10^{9} / 1\right)$, but this had returned to within the reference range at subsequent visits.

There was a tendency for adjusted calcium concentrations to move from normal to low normal in tiludronate recipients. However, these abnormalities were not considered to be of clinical significance by the investigators.

Adverse events were classified according to the WHO scheme. ${ }^{16} \mathrm{~A}$ total of 164 adverse events were reported by 79 patients; those occurring in seven or more patients are shown in table 3. The incidence of adverse events was higher on tiludronate (65/86 patients $(76 \%)$ ) than on placebo $(14 / 26$ patients $(54 \%))$ and was dose-related. The majority $(54 \%)$ of adverse events were mild and $56 \%$ of adverse events were not thought to be related to the study medication. Previous treatment with bisphosphonates did not alter the incidence of adverse events.

Two deaths were reported during the study. One was due to pulmonary embolus and the

Table 3 Number of patients reporting an adverse event (\%)

\begin{tabular}{|c|c|c|c|c|c|}
\hline & \multirow{2}{*}{$\begin{array}{l}\text { Placebo } \\
(n=26)\end{array}$} & \multicolumn{3}{|l|}{ Tiludronate } & \multirow[b]{2}{*}{$p$-value $\dagger$} \\
\hline & & $200 \mathrm{mg}(n=29)$ & $400 m g(n=29)$ & $600 m g(n=28)$ & \\
\hline Nausea & $2(7.7)$ & $5(17.2)$ & $3(10.3)$ & $7(25.0)$ & 0.351 \\
\hline Diarrhoea ${ }^{\star}$ & $0(0.0)$ & $3(10.3)$ & $4(13.8)$ & $7(25.0)$ & 0.037 \\
\hline Arthralgia & $2(7.7)$ & $5(17.2)$ & $1(3.4)$ & $2(7.1)$ & 1.00 \\
\hline Dyspepsia & $0(0.0)$ & $3(10.3)$ & $1(3.4)$ & $5(17.9)$ & 0.114 \\
\hline Skeletal pain & $3(11.5)$ & $1(3.4)$ & $1(3.4)$ & $3(10.7)$ & 0.385 \\
\hline Vomiting & $0(0.0)$ & $1(3.4)$ & $0(0.0)$ & $6(21.4)$ & 0.198 \\
\hline
\end{tabular}

^Significantly higher incidence on tiludronate than on placebo. There were no other significant differences between placebo and tiludronate. †Fisher's exact test: 2-tailed, placebo vs all tiludronate 
other followed a myocardial infarction; neither event was attributed to study medication. Of the seven patients withdrawn because of adverse events, four were considered to be related to study medication: two from the 600 $\mathrm{mg}$ dose group (both for gastrointestinal symptoms), one from the $200 \mathrm{mg}$ dose group (also gastrointestinal) and one on placebo (asthenia/dizziness). The most common adverse events were gastrointestinal $(38 \%)$ with diarrhoea occurring significantly more often on tiludronate than on placebo $(p=0.0372)$, but none were considered serious. The number of gastrointestinal events was dose-related (placebo: four, $200-\mathrm{mg}$ group: 18, 400-mg group: nine, $600-\mathrm{mg}$ group: 31 ). The higher incidence of gastrointestinal adverse events on tiludronate was not related to either concomitant use of nonsteroidal anti-inflammatory agents $(p=0.107)$ or a previous history of gastrointestinal disorders at entry $(p=0.969)$.

There was one traumatic fracture which occurred during the study after 21 days treatment with $400 \mathrm{mg}$ daily involving a nonPagetic rib.

\section{FOLLOW-UP}

Eighteen months after the last patient had completed the trial, patients who had completed at least 11 weeks of treatment were followed-up to assess the sustained clinical efficacy of tiludronate. Efficacy was assessed in terms of time interval between completion of the initial study and further treatment, number of patients requiring retreatment with a specific anti-Pagetic agent, number of patients suffering from complications of Paget's disease, and serum alkaline phosphatase concentrations.

Of the original 112 patients entered into the study, 98 were eligible for follow-up. Of the remaining 14 patients, five were withdrawn for protocol violations (three on placebo, one each on $400 \mathrm{mg}$ and $600 \mathrm{mg}$ ), one had insufficient treatment duration (placebo), five had adverse events (two each on $200 \mathrm{mg}$ and $600 \mathrm{mg}$, one on $400 \mathrm{mg}$ ), one dropped out $(200 \mathrm{mg})$ and two died (both on $200 \mathrm{mg}$ ). Completed questionnaires were returned on 85 patients (19 for placebo, 22 for each of the tiludronate groups).

Thirty-six patients had required retreatment for Paget's disease since the end of the original study (table 4). The reasons for retreatment stated by the investigators were pain (three), deterioration of Paget's disease (26) and serum alkaline phosphatase raised $30 \%$ above the end of treatment concentration (seven). There was a distinct dose-dependent effect on the number of patients deemed as needing retreatment between treatments, with doses of $400 \mathrm{mg}$ $(\mathrm{p}=0.019)$ and $600 \mathrm{mg}(\mathrm{p}=0.008)$ tiludronate being significantly different from placebo. The period of time until first retreatment or last review (if without further treatment) showed a statistically significant increase in 'treatmentfree time' for all the treatment groups compared with placebo $(p=0.043,0.002$, and 0.001 for $200 \mathrm{mg}, 400 \mathrm{mg}$, and $600 \mathrm{mg}$ tiludronate, respectively). However, there was no evidence of differences in 'treatment-free time' between the tiludronate groups.

Fourteen patients experienced a complication of Paget's disease (including pain) during the follow-up period (table 4). There was a statistically significant reduction in the $400 \mathrm{mg}$ tiludronate group compared with placebo $(p=0.029)$ and comparisons between $600 \mathrm{mg}$ tiludronate and placebo approached significance $(p=0.078)$. Analysis of the decrease in mean serum alkaline phosphatase concentrations against time showed a dose-related effect. For all tiludronate groups the reduced concentrations following treatment were maintained for a plateau phase which lasted for several months. The subsequent slow increase in serum alkaline phosphatase concentrations reflected a gradual increase in disease activity. The dose-response relationship observed during the six-month trial period persisted throughout the follow-up period, as illustrated in figure 3.

\section{Discussion}

Bisphosphonates have a low oral bioavailability $^{17}$ which may be markedly altered by formulation changes, with consequent effects upon efficacy and tolerability. In this study, for example, a 400-mg tablet showed a similar effect to that previously demonstrated by an 800 -mg capsule, ${ }^{14}$ the difference being ascribed to the addition of sodium lauryl sulphate to the formulation.

The results showed that $400 \mathrm{mg}$ tiludronate daily for 12 weeks was associated with a reduction of mean serum alkaline phosphatase concentrations by $67 \%$ at the end of 24 weeks. In this dosing group, $70 \%$ of the patients showed a $50 \%$ fall in serum alkaline phosphatase concentrations and $96 \%$ showed a $25 \%$ fall (used as an efficacy criterion in some studies $\left.{ }^{18}\right)$. The proportion of patients in the 400-mg group whose serum alkaline phosphatase concentration was normalised was $39 \%$.

Table 4 Results of the follow-up survey, 18 months after completion of study

\begin{tabular}{|c|c|c|c|c|}
\hline & \multirow[b]{2}{*}{ Placebo $(n=19)$} & \multicolumn{3}{|l|}{ Tiludronate } \\
\hline & & $200 \mathrm{mg}(n=22)$ & $400 \mathrm{mg}(n=22)$ & $600 \mathrm{mg}(n=22)$ \\
\hline $\begin{array}{l}\text { Number of patients } \\
\text { requiring retreatment }\end{array}$ & 13 & 10 & 7 & 6 \\
\hline $\begin{array}{l}\text { Time until lower quartile } \\
(25 \%) \text { retreatment (days) }\end{array}$ & 153 & 489 & 728 & 707 \\
\hline Complications of Paget's disease & 6 & 5 & 1 & 2 \\
\hline
\end{tabular}

*At the time of survey the $400 \mathrm{mg}$ and $600 \mathrm{mg}$ tiludronate groups had not reached median (50\%) retreatment time, therefore the lower quartile (25\%) was compared 


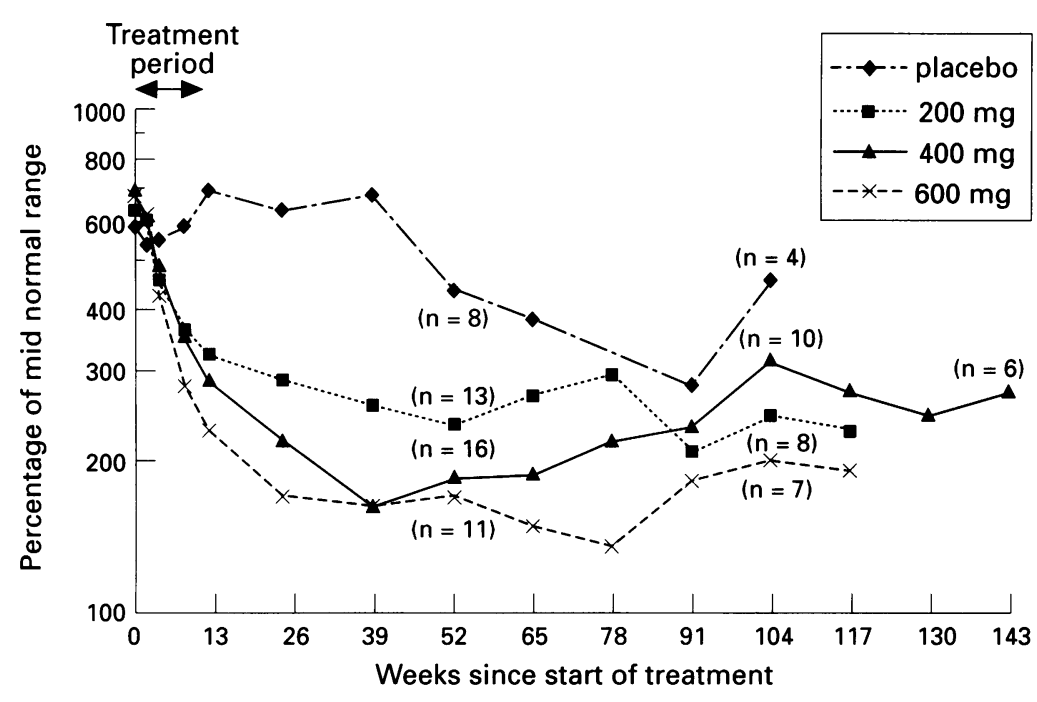

Figure 3 Change in mean percentage of mid-normal range of serum alkaline phosphatase over time. Data points for the post-study period (after week 24) are plotted as rolling three-month means where $n>3$

This level of response is similar to that reported for higher doses of etidronate $(20 \mathrm{mg} / \mathrm{kg})$ and for other bisphosphonates, as reviewed by Kanis, ${ }^{5}$ and is higher than previously observed with injected calcitonin $\left(25 \%{ }^{19}\right)$. The results for $600 \mathrm{mg}$ tiludronate were slightly higher than for $400 \mathrm{mg}$ with $82 \%$ of patients achieving a $50 \%$ reduction in concentrations (mean reduction $74 \%$ ) and $44 \%$ of patients achieving normalisation. Tiludronate maintained its suppression of serum alkaline phosphatase 12 weeks after withdrawal of treatment and its efficacy was unaltered by prior bisphosphonate therapy.

Tiludronate produced rapid, marked reduction of hydroxyproline:creatinine ratios, indicating that its chief action is to inhibit osteoclast activity. The percentage reduction in this ratio was approximately equal for 400 $\mathrm{mg}$ and $600 \mathrm{mg}$ tiludronate $(66 \%$ and $67 \%$, respectively), although the $400 \mathrm{mg}$ group had a higher mean hydroxyproline:creatinine ratio at baseline $(0.073$ compared with 0.052 for the $600 \mathrm{mg}$ group).

Tiludronate was associated with few serious adverse events of clinical significance. However, as with other bisphosphonates, a doserelated increase in gastrointestinal symptoms was observed. These symptoms often resolved spontaneously, but occasionally required treatment to be discontinued. While $75 \%(21 / 28)$ of patients receiving $600 \mathrm{mg}$ of tiludronate had gastrointestinal symptoms only $31 \%(9 / 29)$ of those on $400 \mathrm{mg}$ reported similar complaints.

Although pain was a secondary endpoint for efficacy in this study, only $63 \%$ of patients complained of Pagetic pain at entry. The percentage of patients reporting Pagetic bone pain after 24 weeks exhibited an apparent dose response, being $67 \%, 53 \%, 46 \%$, and $37 \%$, on placebo, $200 \mathrm{mg}, 400 \mathrm{mg}$, and $600 \mathrm{mg}$, respectively); however the difference from placebo was not significant.

The efficacy of a treatment for Paget's disease may be assessed either by direct clinical endpoints or biochemically. Biochemical as- sessment is a recognised surrogate marker of disease activity which affords the opportunity to assess the effect of the therapy across the whole population. Clinical endpoints can be used to demonstrate patient outcome in terms of symptomatology. However, in the case of Paget's disease these criteria may either be difficult to define (difficulty in distinguishing the source of the pain and the frequency of arthritis in Paget's disease ${ }^{2,3}$ ) or, as in the case of complications, may tend to occur infrequently.

The follow-up survey of the patients treated in this study shows that tiludronate has a significantly more sustained effect on both clinical and biochemical endpoints when compared with placebo. Fewer patients had required retreatment and the time until retreatment was significantly greater for all three tiludronate groups than with placebo. The number of complications of Paget's disease was significantly less than placebo with $400 \mathrm{mg}$ tiludronate and approached significance with $600 \mathrm{mg}$ tiludronate.

The survey also shows that, even after serum alkaline phosphatase concentrations stop falling (which may be some months after treatment has stopped), there is a plateau phase which lasts for several months before there is any evidence of a slow increase towards pretreatment concentrations. The effect shows a dose responsiveness. The apparent fall in serum alkaline phosphatase with increased follow-up results from the exclusion of patients who had been retreated from this analysis. Nevertheless this is only markedly apparent in the placebo and 200-mg treatment groups prior to two years (see figure 3).

The bisphosphonates have superseded the calcitonins as first-line therapy for Paget's disease of bone, but only etidronate, a first generation bisphosphonate, is widely available orally and its efficacy is limited by simultaneous inhibition of mineralisation. The present study has shown that oral tiludronate is clearly an effective, well-tolerated treatment for $\mathrm{Pa}$ get's disease. In a study comparing $400 \mathrm{mg} /$ day tiludronate tablets with etidronate, ${ }^{20}$ using identical success criteria, it has been shown that at three and six months the percentage of patients with a successful outcome was greater for tiludronate. The tiludronate results were consistent with those seen in the current study.

The results of the present study suggest that a daily dose of $400 \mathrm{mg}$ tiludronate tablets for

\section{Summary/learning points}

- oral tiludronate is an effective and well tolerated treatment of Paget's disease of bone

- the reduction in alkaline phosphatase observed with tiludronate demonstrates a dose response

- adverse events are dose-related and the only adverse event that had a statistically significantly higher incidence with tiludronate compared to placebo was diarrhoea $(p=0.037)$

- tiludronate in a dose of $400 \mathrm{mg}$ once daily for three months offers the optimum balance of efficacy and tolerance 
12 weeks offers an optimum balance of efficacy and safety.

The authors gratefully acknowledge the contributions of the physicians who participated in this study: K Rajan, Pontypridd; M Davies, Manchester; R Francis, Newcastle; DR Swinson, Wrightington Hospital; D Heath, Birmingham; R Tallis, Salford; A Bhalla, Bath; R Gray, Guildford; C Paterson,

1 Detherige FM, Guyer PB, Barker DJ. European distribuion of Paget's disease of bone. BMF 1982; 285: 1005-8.

2 Kanis JA. Clinical features and complications. In: Pathophysiology and treatment of Paget's disease of bone. London: Martin Dunitz Ltd, 1991; pp 110-38.

3 Winfield J, Stamp TCB. Bone and joint symptoms in Paget's disease. Ann Rheum Dis 1984; 43: 769-73.

4 Wallach S. Comparative effects of salmon, human and eel calcitonins on skeletal turnover in human disease. In: The effects of calcitonins in man. Milan: Masson Italia, 1983; pp $141-51$.

5 Kanis JA. Drugs used for the treatment of Paget's disease. In: Pathophysiology and treatment of Paget's disease of bone. In: Pathophysiology and treatment of Paget's disease

6 DeRose J, Singer FR, Avramides A, et al. Response of Paget's disease to porcine and salmon calcitonins. Effects of long-term treatment. Am 7 Med 1974; 56: 858-66.

7 Bastian J, Aldred JP, Lesh JB, Kleszynski RR. Clinical experience in Paget's disease with porcine and salmon calcitonin. In: Hioco J, ed, La maladie de Paget. Symposium International, fune 20-23 1973; Le Mas D'Artigny - St Paul de Vence. Laboratoire Armour Montagu, 1977; pp 270-9.

8 Grunstein HS, Clifton-Bligh P, Posen S. Paget's disease of bone. Experiences with 100 patients treated with salmon calcitonin. Med F Aust 1981; Sep: 278-80.

9 MacIntyre I, Evans IM, Hobitz HH, Joplin GF, Stevenson JC. Chemistry, physiology, and therapeutic applications of calcitonin. Arthritis Rheum 1980; 23: 1139-47.

10 Fleisch H. Diphosphonates: history and mechanisms of action. Metab Bone Dis Rel Res 1981; 4: 279-88.

11 Cantrill JA, Anderson JA. Treatment of Paget's disease of bone. Clin Endocrinol (Oxf) 1990; 32: 507-18.
Dundee; R Buckle, Southampton; A Crisp, Cambridge; P Klimiuk, Oldham; D Reid, Aberdeen; P Belchetz, Leeds.

Was supported by Sanon Winthrop Ltd. We thank Mr N Brayshaw (statistician) for his contribution.

12 Boyce BF, Fogelman I, Ralston S, Smith L, Johnston E Boyle IT. Focal osteomalacia due to low dose diphosphonate therapy in Paget's disease. Lancet 1984; i: 821 - 4 3 Reginster JY. Oral tiludronate: pharmacological properties and potential usefulness in Paget's disease of bone and osteoporosis. Bone 1992; 13: $351-4$.

14 Reginster JY, Colson F, Morlock G, Combe B, Ethgen D Geusens P. Evaluation of the efficacy and safety of ora tiludronate in Paget's disease of bone. A double-blind, multiple-dosage, placebo-controlled study. Arthritis Rheum 1992; 35: $967-74$.

5 Huskisson EC. Measurement of pain. Lancet 1974; ii $1127-31$.

16 WHO Collaborative Centre for International Drug Monitoring. International monitoring of adverse reaction to drugs:adverse reaction terminology, 1991.

17 Recker RR, Saville PD. Intestinal absorption of disodium ethane-1-hydroxyl-1, 1-diphosphonate (disodium etidronate) using a deconvolution technique. Toxicol Appl Pharmacol 1973; 24: $580-9$.

18 Gray RE, Yates JP, Preston CJ, Smith R, Russell RCG, Kanis JA. Duration of effect of oral diphosphonate therapy in Paget's disease of bone. $Q \mathcal{F}$ Med 1987; 64: 755-67.

19 Hamilton CR. Effects of synthetic salmon calcitonin in patients with Paget's disease of bone. Am F Med 1974; 56: $315-22$.

20 Roux C, Gennari C Farrerons J, et al Comparative prospective double-blind multicentre study of the efficacy prospective double-blind multicentre study of the efficacy Arthritis Rheum 1995; 38: 851 -8. 